\title{
THE EFFECT OF CARBON DIOXIDE ON THE PULMONARY CIRCULATION IN CONGENITAL HEART DISEASE*
}

\author{
BY \\ R. J. SHEPHARD \\ From The Cardiac Department, Guy's Hospital
}

Received July 26, 1954

The response of the pulmonary vessels to the stimulus of an increased carbon dioxide concentration has been examined in a number of experimental animals, but the results have been conflicting. Most investigations have centred on the measurement of pulmonary arterial pressure, and it must be remembered that this value gives an indication of the tone of the pulmonary arterioles only if account is taken of the rate of pulmonary flow and of possible back-pressure effects from the pulmonary venous system.

Much early work served mainly to emphasize the labile nature of responses in the pulmonary circulation. Thus Löhr (1924) found vaso-constrictive changes in the isolated cat lung, but noted that this effect could easily be reversed by a trace of adrenaline in the perfusate. Euler and Liljestrand (1946), recording pulmonary arterial pressures in the intact cat, were unable to show any effect from carbon dioxide until a concentration of 6.5 per cent was reached. Above this level there appeared to be a small increase in pressure, but it was admitted that this might be due to coincident changes in left atrial pressure and cardiac output. Nisell (1950), in further studies with the isolated cat lung, again found a rather variable response: in some instances there was a rise of pulmonary arterial pressure with carbon dioxide concentrations as low as 2 per cent, this effect appearing after a short latent period of some 30-60 seconds. A vaso-constrictor response to high concentrations of carbon dioxide has also been shown in the monkey (Hebb and Nimmo-Smith, 1949), this effect being more obvious after some hours perfusion. It would seem, therefore, that the response to carbon dioxide is in some way enhanced by a decrease in vitality of the preparation. A further complicating factor is a possible species variation in the effect of carbon dioxide on the bronchial musculature (Hebb and Nimmo-Smith, 1949). Where pressures are recorded from isolated lungs, or even from openchested animal preparations, the altered extra-pulmonary pressure relationships can produce large changes in the capacity of the pulmonary vessels (Ochsner, 1952).

With the advent of cardiac catheterization, observations on the pulmonary circulation of human subjects have been possible. Such studies eliminate the difficulties of species variation, disturbed external pressure-relationships, and ageing preparations. However, data must for the most part be obtained from pathological subjects, and the actual procedure of catheterization exposes such subjects to considerable emotional stress. Motley et al. (1947), using this technique, considered the effects of hypoxia and were able to demonstrate a rise in pulmonary arterial pressures similar to that found previously in experimental animals. However, the method does not yet seem to have been applied to an investigation of the effects of carbon dioxide on the human pulmonary circulation.

In the present study, pressure/flow relationships in the pulmonary circulation of a group of twenty patients with congenital heart disease have been analysed before and during the administration of a 5 per cent mixture of carbon dioxide in air.

* This work has been submitted in part fulfilment of the requirements of a Ph.D. degree in the Faculty of Science, University of London. 


\section{METHODS}

Measurements of Pulmonary Flow and Pressures. The technique of cardiac catheterization used in this hospital has been described previously (Holling and Zak, 1950). Two factors must be considered in the application of the Fick principle during the breathing of carbon dioxide mixtures. Firstly, there is a slight increase in oxygen consumption due to the metabolic cost of hyperventilation: after a three-minute period of hyperventilation, this increase amounts to some 3 per cent of the basal level (Shephard, 1954), and the initial spirometer reading must be corrected accordingly. Secondly, the oxygen content of alveolar gas is increased by 2.6 to 2.8 per cent (Shephard, 1954), and this produces a small increase in the amount of oxygen dissolved in physical solution in the blood. Correction must be applied for this also if an accurate value for cardiac output is to be obtained.

The pulmonary arterial and pulmonary capillary pressures were measured by electromanometer (Southern Instruments, Ltd., Camberley).

The mixture of 5 per cent carbon dioxide in air was supplied to the patients via a B.L.B. mask at a rate of 9 litres a minute.

Subjects. The subjects were drawn from cases of congenital heart disease submitted for diagnostic cardiac catheterization. The only factor that influenced their selection was the degree of cooperation shown during the initial diagnostic procedures. In all observations the subjects were lying horizontally, and pressures have been referred to the mid-axillary line.

\section{Pressure/Flow Relationships Found in the Pulmonary Artery}

Pressure/flow relationships were studied with the tip of the catheter lying in the right pulmonary artery about one inch beyond the bifurcation of the pulmonary trunk, the position being checked by fluoroscopy before and after the measurements were made. A blood sample was withdrawn after breathing the gas-mixture for three minutes; phasic and mean pulmonary artery pressures were recorded immediately before and immediately after taking the sample, the average of the two readings being taken as representative of pressures during sampling.

Pulmonary Arterial Pressures. The change of pulmonary arterial pressure which has been produced by the 5 per cent mixture of carbon dioxide is illustrated in Fig. 1. It can be seen that

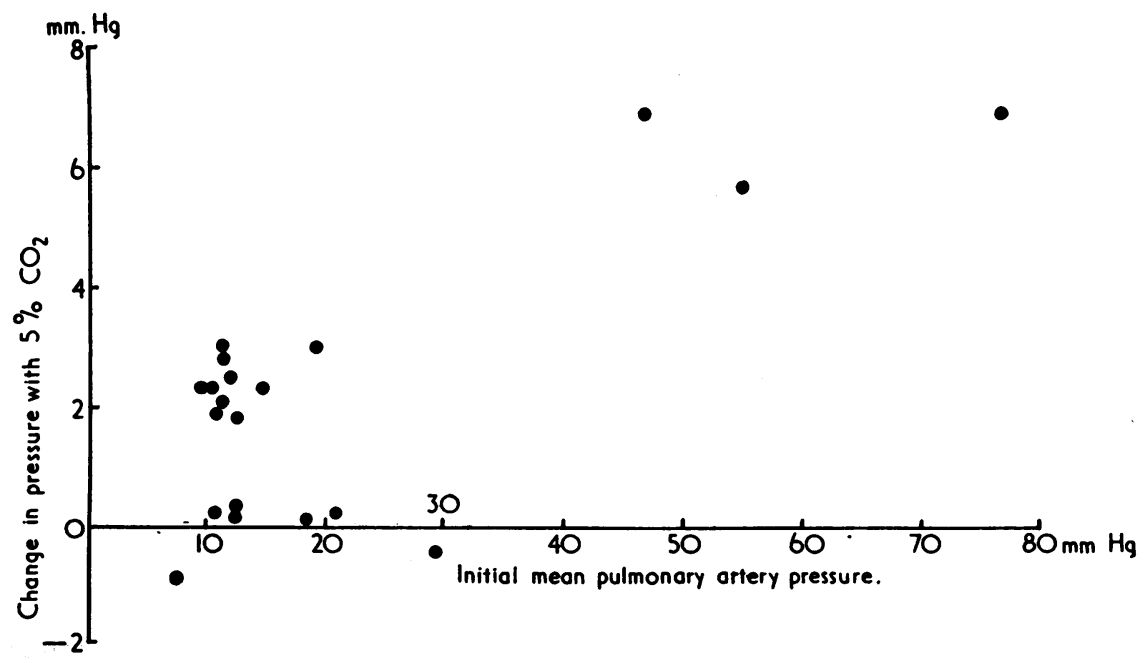

FIG. 1.-Changes in Pulmonary Arterial Pressure with 5 per cent Carbon Dioxide. Twenty cases of congenital heart disease. A 5 per cent mixture of carbon dioxide in air was supplied by B.L.B. mask for a period of three minutes. Note that the increase of pressure is somewhat greater in those patients with a high initial pressure. 
there is a small but consistent increase in mean pressure. The magnitude of this change is perhaps rather greater in those patients with a high initial pressure (Table I), particularly in cases with a left-to-right shunt (Case 1, atrial septal defect; Case 7, ventricular septal defect; and Case 18, patent ductus arteriosus).

TABLE I

Pulmonary Arterial Pressures before and after Breathing a 5\% Mixture of Carbon Dioxide in air

\begin{tabular}{|c|c|c|c|c|}
\hline $\begin{array}{l}\text { Case, sex, } \\
\text { and age }\end{array}$ & Diagnosis & $\begin{array}{l}\text { Pulmonary artery } \\
\text { pressure breathing } \\
\text { air }(\mathrm{mm} . \mathrm{Hg})\end{array}$ & $\begin{array}{l}\text { Pulmonary artery } \\
\text { pressure breathing } \\
\text { air }+5 \% \mathrm{CO}_{2} \\
(\mathrm{~mm} . \mathrm{Hg})\end{array}$ & $\begin{array}{c}\text { Change } \\
\text { (mm. Hg) }\end{array}$ \\
\hline $\begin{array}{rl}1 & F .44 \\
2 & \text { M.21 } \\
3 & \text { F.14 } \\
4 & \text { F.14 } \\
5 & \text { M.14 } \\
6 & \text { F.21 } \\
7 & F .22 \\
8 & \text { F.11 } \\
9 & \text { F.11 } \\
10 & \text { F.48 } \\
11 & \text { F. } 9 \\
12 & \text { F. } 9 \\
13 & \text { M.19 } \\
14 & \text { M.21 } \\
15 & \text { F.34 } \\
16 & \text { M.10 } \\
17 & \text { M.8 } \\
18 & \text { F.45 } \\
19 & \text { M.26 } \\
20 & \text { F.21 }\end{array}$ & $\begin{array}{l}\text { Atrial septal defect } \\
\text { Pulmonary stenosis } \\
\text { Patent ductus arteriosus } \\
\text { Pulmonary stenosis } \\
\text { Ventricular septal defect } \\
\text { Pulmonary stenosis } \\
\text { Ventricular septal defect } \\
\text { Fallot's tetralogy } \\
\text { Pulmonary stenosis } \\
\text { Fallot's tetralogy } \\
\text { Patent ductus arteriosus } \\
\text { Fallot's tetralogy } \\
\text { Pulmonary stenosis } \\
\text { Pulmonary stenosis } \\
\text { Pulmonary stenosis } \\
\text { Aortic stenosis } \\
\text { Normal heart } \\
\text { Patent ductus arteriosus } \\
\text { Fallot's tetralogy } \\
\text { Pulmonary stenosis }\end{array}$ & 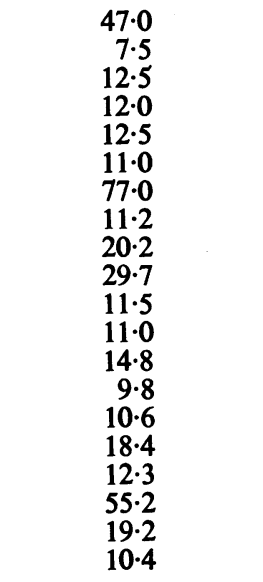 & $\begin{array}{l}53 \cdot 9 \\
6 \cdot 8 \\
12 \cdot 8 \\
14 \cdot 5 \\
14 \cdot 3 \\
12 \cdot 9 \\
83 \cdot 9 \\
13 \cdot 3 \\
20 \cdot 4 \\
29 \cdot 3 \\
14 \cdot 5 \\
13 \cdot 8 \\
17 \cdot 1 \\
12 \cdot 1 \\
12.9 \\
18 \cdot 5 \\
12 \cdot 5 \\
60 \cdot 9 \\
22 \cdot 2 \\
10 \cdot 6\end{array}$ & $\begin{array}{l}+6.9 \\
-0.7 \\
+0.3 \\
+2.5 \\
+1.8 \\
+1.9 \\
+6.7 \\
+2.1 \\
+0.2 \\
+0.4 \\
+3.0 \\
+2.8 \\
+2.3 \\
+2.3 \\
+2.3 \\
+0.1 \\
+0.2 \\
+5.7 \\
+3.0 \\
+0.2\end{array}$ \\
\hline
\end{tabular}

Part of the increase in pressure may be attributable to back-pressure effects from the left atrium. It did not prove possible to measure the left atrial pressure directly in any of the present series, although in a number of instances satisfactory pulmonary capillary pressure records were obtained. The original contention of Lagerlof and Werkö (1949) that such records give an approximate value for left atrial pressure has since been criticized (Dow et al., 1950), but it is at present the only method applicable to most patients. The results show that in some instances the pulmonary capillary pressure is increased (Table II). However, in all except one of these, the hæmodynamic pressure gradient across the lungs is also slightly increased.

Pulmonary Flow. A change of cardiac output during the breathing of carbon dioxide mixtures has previously been reported by Asmussen (1943), this change being greatest when his subjects

TABLE II

Changes in Pulmonary Capillary Pressure associated with Breathing of 5 per cent Mixture of Carbon DIOXIDE IN AIR

\begin{tabular}{|c|c|c|c|c|c|c|}
\hline \multirow[t]{2}{*}{ Observation No. } & \multicolumn{3}{|c|}{ Breathing air } & \multicolumn{3}{|c|}{ Breathing air $+5 \% \mathrm{CO}_{2}$} \\
\hline & P.A. & P.C. & Gradient & P.A. & P.C. & Gradient \\
\hline $\begin{array}{r}6 \\
7 \\
12 \\
13 \\
14 \\
16\end{array}$ & $\begin{array}{c}\mathrm{mm} . \mathrm{Hg} \\
11.0 \\
77.0 \\
11.0 \\
14.8 \\
9.8 \\
18.4\end{array}$ & $\begin{array}{c}\text { mm. Hg } \\
6.5 \\
8.9 \\
9 \cdot 2 \\
8.1 \\
5.5 \\
9.0\end{array}$ & $\begin{array}{c}\text { mm. } \mathrm{Hg} \\
4 \cdot 5 \\
68 \cdot 1 \\
1 \cdot 8 \\
6 \cdot 7 \\
4 \cdot 3 \\
9 \cdot 4\end{array}$ & $\begin{array}{c}\text { mm. } \mathbf{H g} \\
12.9 \\
83.9 \\
13 \cdot 8 \\
17 \cdot 1 \\
12 \cdot 1 \\
18.5\end{array}$ & $\begin{array}{c}\mathrm{mm}_{6} . \mathrm{Hg} \\
6 \cdot 3 \\
10 \cdot 8 \\
9 \cdot 1 \\
9 \cdot 2 \\
7 \cdot 7 \\
10 \cdot 6\end{array}$ & $\begin{array}{c}\text { mm. } \mathbf{H g} \\
6.6 \\
73.1 \\
4.7 \\
7.9 \\
4.4 \\
7.9\end{array}$ \\
\hline Mean value & & $7 \cdot 9$ & & & $9 \cdot 0$ & \\
\hline
\end{tabular}


were supine. A similar result might be anticipated in the present series from the rise in left atrial pressure noted above, and the calculated cardiac output does in fact show a significant rise for the group (Table III).

Pulmonary Arteriolar Resistance. It is of some interest to consider whether this increase in cardiac output is adequate to account for the observed rise in pulmonary pressure gradient, or whether there has been also some change in the level of pulmonary arteriolar resistance.*

TABLE III

Increase in Pulmonary Flow on Changing from Air to a 5 per cent Carbon Dioxide

\begin{tabular}{|c|c|c|c|}
\hline Case & $\begin{array}{c}\text { Pulmonary flow } \\
\text { (Air) } \\
\text { L/min. }\end{array}$ & $\begin{array}{c}\text { Pulmonary flow } \\
\left(\mathrm{Air}+5 \% \mathrm{CO}_{2}\right) \\
\text { L/min. }\end{array}$ & $\begin{array}{c}\text { Change } \\
(\%)\end{array}$ \\
\hline \multirow[t]{2}{*}{$\begin{array}{r}1 \\
2 \\
3 \\
4 \\
5 \\
6 \\
7 \\
8 \\
9 \\
10 \\
11 \\
12 \\
13 \\
14 \\
15 \\
16 \\
17 \\
18 \\
19 \\
20\end{array}$} & $\begin{array}{r}16 \cdot 65 \\
3.88 \\
7 \cdot 47 \\
6.58 \\
8 \cdot 75 \\
5 \cdot 10 \\
6.08 \\
1.66 \\
3.09 \\
1.69 \\
3.57 \\
3.32 \\
4.03 \\
8.74 \\
4.98 \\
8.09 \\
8.92 \\
13.20 \\
6.36 \\
5.85\end{array}$ & $\begin{array}{r}15 \cdot 95 \\
4 \cdot 07 \\
7 \cdot 22 \\
7 \cdot 16 \\
7 \cdot 89 \\
5 \cdot 82 \\
7 \cdot 33 \\
1 \cdot 58 \\
3 \cdot 18 \\
2 \cdot 18 \\
4 \cdot 00 \\
3.91 \\
3 \cdot 58 \\
10 \cdot 30 \\
5 \cdot 34 \\
6 \cdot 96 \\
13 \cdot 76 \\
22 \cdot 80 \\
7 \cdot 13 \\
6 \cdot 83\end{array}$ & $\begin{array}{l}-4.3 \\
+4.6 \\
-4.0 \\
+8.2 \\
-11.4 \\
+14.2 \\
+20.6 \\
+3.6 \\
+2.9 \\
+29.0 \\
+20.1 \\
+17.8 \\
+8.9 \\
+38.8 \\
+7 \cdot 2 \\
-16.3 \\
+54.1 \\
+72.8 \\
+12.4 \\
+16.8\end{array}$ \\
\hline & & $\begin{array}{l}\text { e in pulmonary flow } \\
\qquad \begin{array}{l}S m \\
P\end{array}\end{array}$ & $\begin{array}{r}+13.58 \\
\pm 4.8 \\
2.83 \\
0.01\end{array}$ \\
\hline
\end{tabular}

The principal obstacle to the calculation of pulmonary arteriolar resistance is the difficulty in estimating left atrial pressure. In a number of subjects it was not possible to obtain satisfactory pulmonary capillary pressure tracings, and it has therefore been necessary to assume an arbitrary value. The true left atrial pressure is probably rather lower than the pulmonary capillary reading would suggest, so that the values adopted were $5 \mathrm{~mm}$. $\mathrm{Hg}$ for the resting state, and $6 \mathrm{~mm}$. for the pressure after three minutes of carbon dioxide inhalation.

Calculating the pulmonary arteriolar resistance on this basis, it can be seen that the group as a whole shows no significant change of resistance with the breathing of a carbon dioxide mixture (Fig. 2). Further, if the change of resistance is plotted against the change of cardiac output, an obvious negative correlation is obtained, emphasizing that the changes which occur in the pulmonary circulation are largely passive in type, pulmonary resistance falling as the rate of flow increases (Fig. 3). However, the fall of resistance is insufficient to prevent some rise of pressure in most cases. The regression line of Fig. 3 indicates a small increase in resistance at the point where flow is unchanged, but statistical analysis suggests that this should be accepted as a chance finding rather than as a response to carbon dioxide.

* The pulmonary arteriolar resistance has been calculated from the formula $:$ Resistance $=\frac{P-P}{F} \cdot 1332 \mathrm{dynes} / \mathrm{sec} . / \mathrm{cm} .5$, where $P$ is the main pulmonary artery pressure in $\mathrm{mm} . \mathrm{Hg}, p$ is the left atrial pressure in $\mathrm{mm}$. $\mathrm{Hg}$, and $F$ is the pulmonary flow in $\mathrm{ml}$. per second. 


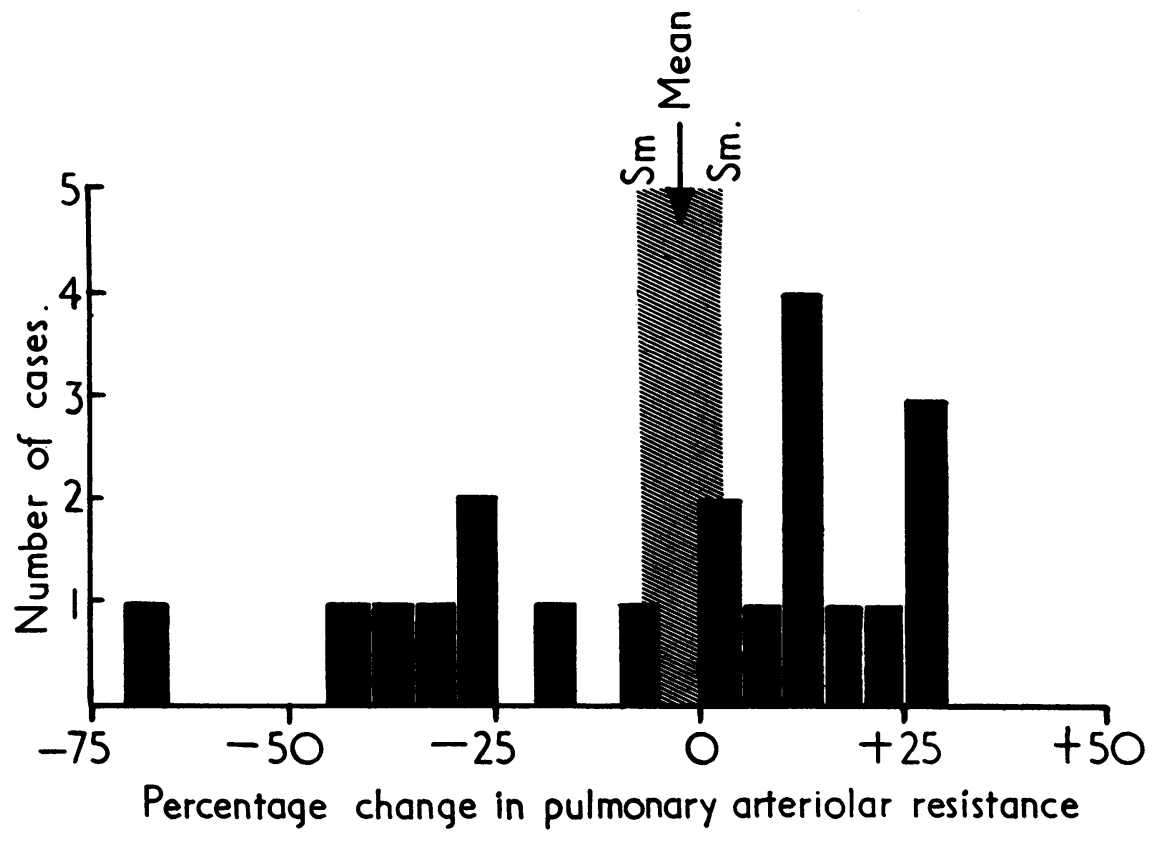

FIG. 2.-Changes in Pulmonary Arteriolar Resistance with 5 per cent Carbon Dioxide. Twenty cases of congenital heart disease. The mean change for the group does not differ significantly from zero (mean $-2 \cdot 6 \%, s_{m} \pm 5 \cdot 9 \%$ ).

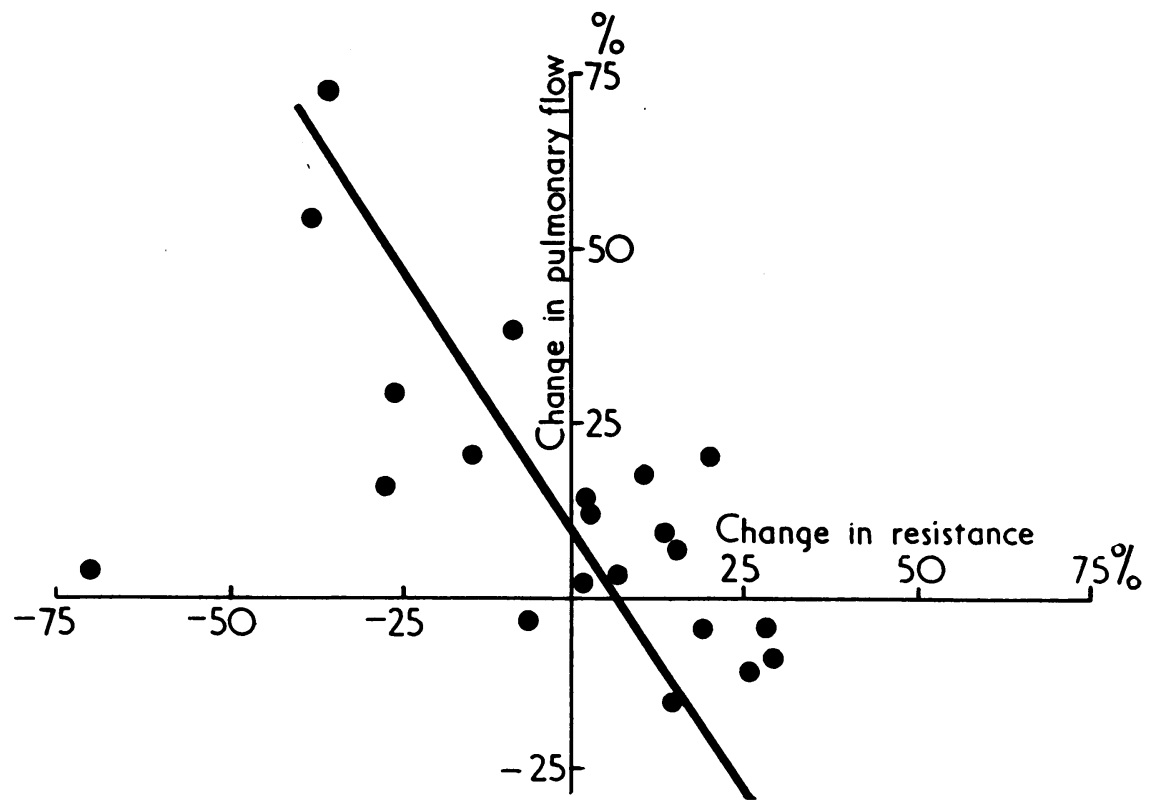

FIG. 3.-Correlation between Changes in Pulmonary Flow and Changes in Pulmonary Arteriolar Resistance. Twenty cases of congenital heart disease. On switching from air to a mixture of 5 per cent carbon dioxide in air for three minutes, the change of resistance varies closely with the change of flow, emphasizing that changes in pulmonary arteriolar resistance are largely passive in type. 
Statistical Analysis. A linear regression line has been fitted to the data by the method of least squares, taking the change in pulmonary arteriolar resistance as the dependent variable. The coefficients to the line then become: $a=-2 \cdot 65, s_{a} \pm 4 \cdot 91, b=-0 \cdot 70, s_{b} \pm 0 \cdot 23$.

Thus for 18 degrees of freedom, the regression has a significance in the range $P=0.01-0.001$. At zero change in flow, the deviation of change in resistance from the hypothetical value of zero is 6.9 , and the standard deviation of this difference is 12.4 . This change in resistance is, therefore, very likely to be a chance finding.

\section{Discussion}

It remains to consider the significance of these findings in health and disease. The rise of pulmonary arterial pressure in response to carbon dioxide mixtures seems to occur in a variety of cases, ranging from low to very high rates of resting pulmonary blood flow, and it is perhaps surprising that a similar rise of pressure is not observed with moderate exercise. In both instances the pulmonary flow is increased, but during moderate exercise there is a fall in pulmonary arteriolar resistance sufficient to keep the pressure within normal limits (Riley et al., 1948). In the present state of knowledge, it is difficult to be certain that this vasodilatation does not constitute the "active" response. However, Cournand (1950) attributes the rise of pressure with anoxia to a local reflex mechanism, which he suggests normally maintains a good correlation between alveolar ventilation and pulmonary arteriolar flow. The stimulus of acute hypercapnia (like acute anoxia) simulates a general alveolar underventilation, and through the same local reflex mechanismperhaps the liberation of a small quantity of histamine-could well produce an alteration in reactivity of the small vessels of the lungs. In the present observations, there is clear evidence that the fall in pulmonary arteriolar resistance with increasing pulmonary flow is insufficient to prevent a rise of pressure, and this failure of adequate vaso-dilatation could be interpreted as due to an increased reactivity of the arterioles. More work is needed to substantiate the existence of a local reflex of this type, but it is obvious that such a mechanism could play an important role in the adjustment of the body to both acute and chronic lung diseases.

\section{SUMMARY}

Pressure/flow relationships have been studied in a group of twenty human subjects at cardiac catheterization, both before and during the breathing of a 5 per cent mixture of carbon dioxide in air.

Carbon dioxide produces a small but consistent rise in pulmonary arterial pressure. Part of this increase is related to back-pressure effects from the left atrium, but in addition there appears to be a genuine increase in the pressure gradient across the lungs. Most subjects show also a small increase in pulmonary blood flow in response to carbon dioxide.

Changes in pulmonary arteriolar resistance appear to be largely passive in type, the resistance falling as the cardiac output rises. However, the fall in resistance is insufficient to prevent some increase in pulmonary pressures. This is unlike the response of the pulmonary circulation to moderate exercise, and may indicate an increased reactivity of the small pulmonary vessels.

\section{REFERENCES}

Asmussen, E. (1943). Acta physiol. Scand., 6, 176.

Cournand, A. (1950). Circulation, 2, 641.

Dow, J. W., and Gorlin, R. (1950). Fed. Proc., 9, 33.

Euler, U. S., and Liljestrand, G. (1946). Acta physiol. Scand., 12, 301.

Hebb, C. O., and Nimmo-Smith, R. H. (1949). Quart. J. exp. Physiol., 34, 159.

Holling, H. E., and Zak, G. (1950). Brit. Heart J., 12, 153.

Lagerlof, H., and Werkö, L. (1949). Scand. J. Lab. Clin. Invest., 1, 147.

Löhr, H. (1924). Z. ges. exp. Med., 39, 67.

Motley, H. L., Cournand, A., Werkö, L., Himmelstein, A., and Dresdale, D. (1947). Amer. J. Physiol., $150,315$.

Nisell, O. (1950). Acta physiol. scand., 21, Supp. 73.

Ochsener, A. (1952). Amer. J. Physiol., 168, 200.

Riley, R. L., Himmelstein, A., Motley, H. L., Weiner, H. M., and Cournand, A. (1948). Amer. J. Physiol., $152,372$. Shephard, R. J. (1954). Unpublished observations. 